First Peoples Child \& Family Review

A Journal on Innovation and Best Practices in Aboriginal Child Welfare Administration,

Research, Policy \& Practice

\title{
Is Attachment Theory Consistent with Aboriginal Parenting Realities?
}

\section{Raymond Neckoway, Keith Brownlee and Bruno Castellan}

Volume 3, Number 2, 2007

Special Issue: Adolescent development, mental health, and promising research directions for Aboriginal youth

URI: https://id.erudit.org/iderudit/1069465ar

DOI: https://doi.org/10.7202/1069465ar

See table of contents

Publisher(s)

First Nations Child and Family Caring Society of Canada

ISSN

1708-489X (print)

2293-6610 (digital)

Explore this journal

Cite this article

Neckoway, R., Brownlee, K. \& Castellan, B. (2007). Is Attachment Theory Consistent with Aboriginal Parenting Realities? First Peoples Child \& Family Review, 3(2), 65-74. https://doi.org/10.7202/1069465ar
Article abstract

Attachment theory has become one of the most influential models guiding parent-child relationships in programs of prevention, treatment, and education, including programs for Aboriginal parents. However, whether the model can be reliably applied when working with Aboriginal peoples has not yet been established. Studies on attachment security conducted with different cultural groups provide a means of comparing naturally occurring differences in parenting practices and socio-emotional environments of children. These studies report inconsistencies of attachment security across cultures and suggest that consideration should be given to cultural differences when applying attachment theory across cultures. In this article, we analyse the correspondence between attachment theory and descriptions of Aboriginal parenting and question the relevance of attachment theory to Aboriginal parents who do not adhere to the mother-infant dyad as the sole contributor to the child's sense of security.
Copyright @ Raymond Neckoway, Keith Brownlee, Bruno Castellan, 2007
This document is protected by copyright law. Use of the services of Érudit (including reproduction) is subject to its terms and conditions, which can be viewed online.

https://apropos.erudit.org/en/users/policy-on-use/ 


\title{
Is Attachment Theory Consistent with Aboriginal Parenting Realities?
}

\author{
Raymond Neckoway ${ }^{a}$, Keith Brownlee ${ }^{a}$, and Bruno Castellan ${ }^{a}$
}

a School of Social Work, Lakehead University, ThunderBay, ON, Canada

\section{Introduction}

Attachment theory has become one of the most important conceptual schemes for understanding the early socio-emotional development of children (Cassidy \& Shaver, 1999; Crittenden \& Claussen, 2000). It has also become one of the most influential models guiding parent-child relationships in key areas such as daycare, child welfare, head start programs, hospitals, schools, and parenting programs. Equally, attachment theory has a central role as a model that informs social work practice with Aboriginal parents even though the applicability of the model for working with Aboriginal peoples has not been established. This raises the question of whether Aboriginal parenting practices are congruent with attachment theory.

Since attachment theory is believed to have a central role in child development, it has been widely incorporated into programs dealing with parent-child relationships. The role of attachment theory in guiding programming for parents is evident in the many references to the theory given in the rationale and design of the programs (Aboriginal Head Start, 2006; McCain \& Mustard, 1999; Rycus \& Hughes, 1998).

Correspondence concerning this article may be addressed to:

Raymond Neckoway

School of Social Work

Lakehead University

955 Oliver Road

Thunder Bay, ON P7B 5E1

(807) 343-8417

Electronic mail may be sent to: raymond.neckoway@ lakeheadu.ca

\begin{abstract}
Attachment theory has become one of the most influential models guiding parent-child relationships in programs of prevention, treatment, and education, including programs for Aboriginal parents. However, whether the model can be reliably applied when working with Aboriginal peoples has not yet been established. Studies on attachment security conducted with different cultural groups provide a means of comparing naturally occurring differences in parenting practices and socio-emotional environments of children. These studies report inconsistencies of attachment security across cultures and suggest that consideration should be given to cultural differences when applying attachment theory across cultures. In this article, we analyse the correspondence between attachment theory and descriptions of Aboriginal parenting and question the relevance of attachment theory to Aboriginal parents who do not adhere to the mother-infant dyad as the sole contributor to the child's sense of security.
\end{abstract}

Despite this widespread adoption of attachment theory, research on the applicability of the model with different cultural groups has been limited. By looking at cultures that do not follow Western child rearing practices, an opportunity emerges to examine naturally occurring differences in parenting and socioemotional environments of children that can clarify the implications of these differences for attachment behaviours. The research that has been conducted, which will be reviewed below, has suggested that parenting practices which differ from Western norms lead to inconsistent results in infant security. This suggests that attachment security as a guiding concept for Aboriginal parents requires further analysis.

In this paper we first provide a brief description of the core ideas in attachment theory. Then, we examine studies that have explored the consistencies of attachment security across cultures, which have raised questions about the cross-cultural applicability 
of the model. Next, we analyse the apparent consistencies or inconsistencies between attachment theory and descriptions of Aboriginal parenting. Finally, we offer some suggestions for applying the model with Aboriginal parents.

\section{Attachment}

Attachment theory has long been recognized as an important model for understanding individual development. Attachment is regarded as significant in shaping our capacity for interpersonal relationships, as well as, in the formulation of our view of the world and of others around us. John Bowlby (1969, 1973, 1980), a British psychoanalyst, is credited with developing attachment theory. Bowlby argued that attachment is biologically based and represents a child's instinctual need for a reliable, ongoing relationship with a primary caregiver and that if this attachment was interrupted, lacking or lost, lasting emotional damage could occur (Karen, 1994). Bowlby focused on the distress that infants tend to show when separated from their mother or the person with whom they are emotionally bonded. Through his research, he identified a series of infant attachment behaviours, including crying, clinging, following and smiling, that he argued serve to keep the caregiver close at hand to ensure the child's safety and survival. He observed that these attachment behaviours were invoked when the distance from the mother (or attachment figure) exceeded a certain threshold in time and/or space and the infant sought to regain proximity.

Bowlby argued that the responsive action or inaction of the primary caretaker to these expressed attachment needs formed the foundation of what he termed the infant's 'internal working model' - a mental representation or belief about the ability and willingness of others around them to provide comfort and care (Ainsworth, Blehar, Waters, \& Wall, 1978; Bowlby, 1969). Thus, he proposed that attachment figures who were able to promptly and consistently provide comfort and reassurance to an infant experiencing distress laid the foundation for an optimal internal working model that enabled the infant to view the world as trusting and responsive and ultimately in terms of a sense of security. Conversely, caregivers who were slow or unable to respond to an infant's expressed needs contributed a foundation for an internal working model that persuaded the infant to view the world through a lens clouded with mistrust and uncertainty (Bowlby, 1973; Bretherton, 1985; Main \& Hesse, 1992). The internal working model is seen as a relatively fixed and lasting schema of the accessibility and quality of the relationship with the attachment figure (Bowlby, 1973). It has further been described as an unconscious blueprint of emotional development that has the potential to impact future relationships (Morton \& Browne, 1998).

Working from Bowlby's premise that initial primary relationships between infant and caregiver could provide insight into relational development, Mary Ainsworth and her colleagues (Ainsworth et al., 1978) laid the groundwork that extended the concept of attachment into a phenomenon open to empirical examination. In an attempt to further analyze and understand the intimate bonding exchange between mother and infant, Ainsworth began strategically observing maternal responsiveness and sensitivity to infant need, proposing that this was the crucial link in the development of infant attachment. In a pivotal study, Ainsworth, Bell and Stayton (1974) demonstrated that mothers' responses to their children varied widely, which in turn could be clearly shown to be linked with the infants' level of secure attachment.

\section{The Strange Situation Procedure}

In her ongoing exploration of the fundamental components of attachment theory, Mary Ainsworth et al. (1978) devised the strange situation procedure (SSP) to test and observe individual differences in infant attachment behaviour. During this procedure, which optimally occurred with infants between twelve to twenty-four months of age, mothers and babies were viewed in an unfamiliar but pleasant environment that invited exploration and play. Through a series of brief episodic encounters, infant behaviour was closely observed under varied conditions of stress: (a) when the mother was separated from the child (leaves the room) after a stranger has entered and begun to interact with the child and (b) when the child was left alone (mother has left the room) whereupon the stranger enters the room and interacts with the child. The infant's responses to the reunion, upon the mother's return on the two occasions of the procedure, were carefully assessed and soon became one of the focal points of the study of attachment behaviour. Based on the systematic observations of Ainsworth and her colleagues (1978), three categories of infant attachment behaviours were proposed. 
Infant responses were labelled as Insecure - Anxious/Avoidant (Type A), Secure (Type B), or Insecure - Anxious-Resistant or Ambivalent (Type C) infants.

Secure - (Type B) infants displayed an optimal level of exploration and caregiver affiliation during the pre-separation phase of the procedure, mild to moderate wariness when the mother left the room and were easily comforted upon her return. It was noted that this group of infants protested or cried when separated from their mothers, but when their mother returned secure infants tended to greet her with pleasure, often reaching out their arms to be picked up and were relatively easily consoled (Karen, 1990).

Anxious-Avoidant - (Type A) infants were observed to be seemingly confident and independent, displayed a relative lack of distress when separated from their mother and avoidance behaviour upon her return. Avoidant infants seemed to be independent. These infants would explore the new environment without seeming to rely on their mothers as a base, and they did not engage in repeated checking on their mother's presence like the infants labelled secure. When the mother left the room, anxious-avoidant infants did not show any marked reaction and when she returned they snubbed or avoided her (Karen, 1990).

Anxious-Resistant or Ambivalent - (Type C) infants showed little interest in exploring their environment; they became highly distressed when left alone or when in the presence of an unfamiliar adult and could not be easily comforted by their mothers. Infants classified as ambivalent were mostly clingy from the beginning of the procedure and seemed fearful about exploring the room on their own. These infants showed a high level of agitation and became very tearful when separated from their caregiver. When the mother returned to the room ambivalent infants sought contact with their mother, but also arched away appearing to be angry and resisted efforts at being soothed (Karen, 1990).

A Disorganized/Disoriented - (Type D) category was suggested by Main and Solomon (1986) to describe another group of infants who seemed to lack any coherence in their responses to the SSP. These children were later found to be in abusive or traumatizing mother-infant relationships that caused a mixture of fearful and uncertain reactions that appeared disorganized and inconsistent (Bretherton, 1985; Main \& Solomon, 1990).
The classifications of infants' secure and insecure attachment behaviours emerged as significant when Ainsworth linked them to in home observations of the mother-infant pairs. From these initial observations specific associations could be made between a mother's style of parenting and the infant's attachment behaviour (Karen, 1990). The infants that had received a classification as securely attached had mothers that responded readily to their infant's communication such as when they cried or otherwise expressed discomfort. These caregivers also reciprocated infants' smiles with an affectionate response. These observations regarding secure attachment confirmed Ainsworth's central premise that a responsive or sensitive mother provides a secure base from which her infant can explore the environment (Ainsworth et al., 1978; Ainsworth \& Marvin, 1994)

In contrast, the mothers of infants labelled as insecurely attached - avoidant (Type A) were found to be insensitive to their infant's expressions of discomfort. These mothers also seemed to display a dislike for physical contact and showed little emotional responsiveness towards their infant (Ainsworth et al., 1978; Bretherton \& Waters, 1985). The mothers of infants labelled as insecurely attached - resistant or ambivalent (Type C), on the other hand, demonstrated a clear inconsistency in responding to their children's needs (Bretherton \& Waters, 1985). Infants labelled as Disorganized (Type D), however, would appear to have experienced both inconsistent and abusive primary relationships characterized by caregiver intrusiveness and maltreatment, including physical abuse and psychological unavailability (Carlson, 1998; Sroufe, Egeland, Carlson, \& Collins, 2005).

The patterns established by these attachment relationships are thought to become internalized by the infant as an internal working model or set of beliefs about what to expect of relationships and this internal model is regarded as stable and resistant to change (Cassidy \& Shaver, 1999). Bowlby (1973) surmised that the beliefs associated with the internal working model persist throughout life. He hypothesized that early attachment success provided a foundation for healthy functioning in future relationships, whereas failure to attach could hinder an individual's ability to form satisfactory relationships later in life and potentially lead to a variety of behavioural and emotional difficulties. Much research has focused on this hypothesis that attachment security predicts 
subsequent behaviour and has tended to confirm an association between attachment types and behaviours during infancy and early childhood, such as play and exploration, autonomy and competence, peer relationships and psychopathology (Sroufe, Fox, \& Pancake, 1983).

The idea that the internal working model is stable and has an enduring effect arising from an individual's secure or insecure level of attachment is a concept with far reaching implications. Thus, attachment patterns are measured by using the SSP and interpreted as secure or insecure. Lasting and stable internal working models are by definition a function of early parenting behaviours, with sensitive parenting leading to the preferred outcome of the secure child. But what if the parenting does not follow attachment theory's ideal pattern, not because the mother or caregiver is insensitive, but because the cultural context in which the child is raised promotes parenting practices that are contrary, or at least, not consistent with the attachment theory ideal.

A number of researchers have pointed out that attachment theory makes assumptions, based on Western ideologies, regarding ideal dyadic relationships and preferred developmental outcomes based on the mother-infant bond (Harwood, Miller, \& Irizarry, 1995; McShane \& Hastings, 2004; Rothbaum, Weisz, Pott, Miyake, \& Morelli, 2000). For instance, not all cultures expect mothers to be the sole caregiver (Bournstein et al., 1992) nor do all cultures interpret the child's needs in the same way (Sagi, 1990) or have the same reactions to emotional expression, such as the meaning of an infant's cry (Harwood et al., 1995). What must surely come into question then, is the universal applicability of attachment theory (van IJzendoorn, 1990). Although there are relatively few studies that have examined the consistency of attachment theory and attachment security across cultures (van IJzendoorn \& Sagi, 1999), there have been studies that have allowed for comparisons between cultures. In the next section we review studies that have examined the pattern of attachment security using the SSP with parents and children from cultures where parenting practices differ from the normative sample from the USA.

\section{Thematic Analysis of Attachment}

Although there are numerous cultural differences in parenting that could be explored, there are three core patterns that are identifiable which have a bearing on attachment theory. First, parenting that is very involved and intensive in meeting infant needs or what we have called 'hypersensitive parenting.' Second, parenting that is less intensive in meeting infant's and what we have called 'selective parenting.' Third, the involvement of multiple caregivers in a significant role in caring for the infant or what we have called 'shared parenting.' We will review studies that have examined the association between these patterns of parenting in different cultures and attachment security.

\section{Hypersensitive Parenting}

In Western culture the expectation is that a parent will respond sensitively to a child's needs as a reaction to explicit signals from the child. In Japanese culture the expectation is different, a parent is expected to engage in a high level of emotional closeness and to anticipate a child's needs rather than wait for a signal from the child (Rothbaum et al., 2000). The Japanese mother is encouraged to view the child as an extension of herself (Bournstein et al., 1992), with close physical contact between the dyad, whereas American mothers "prefer more distal modes of interaction with their baby" (Vereijken, Riksen-Walraven, \& KondoIkemura, 1997, p. 36). The aim in Japanese culture is to promote interdependence while in Western culture the aim is to promote independence of the child (Rothbaum et al., 2000). Thus, Japanese parenting contrasts with what attachment theorists have described as sensitive responding (Ainsworth et al., 1974). Japanese mothers, according to the theory, could be labelled hypersensitive (Gibson, Ungerer, McMahon, Leslie, $\&$ Saunders, 2000). According to attachment theorists this type of interaction could lead to insecurely attached infants, specifically anxious-resistant infants.

Takahashi (1986) conducted a study with Japanese mothers and their infants using the SSP that allowed this assumption to be examined. Takahashi reported that $68 \%$ of the infants were assessed as having a secure attachment with their mother while $32 \%$ were reported as having an anxious-resistant attachment. However, when Takahashi decided to classify the infants on a modified SSP, where only the first five episodes were used and the infant was not left alone in the room, the results were drastically altered. She found that $83 \%$ of infants were rated securely attached and $17 \%$ were classified as having an anx- 
ious-resistant attachment. Durett et al. (1984) studied 39 intact middle class families living in Tokyo with one-year-old infants and reported an attachment distribution of $13 \%$ anxious-avoidant, $61 \%$ secure, $18 \%$ anxious-resistant and $8 \%$ unclassifiable (cited by van IJzendoorn \& Sagi, 1999). Durett et al's distribution of infant classifications is more consistent with global averages. What is noteworthy from the research with Japanese infants is the variety of attachment classification distributions within the culture, the fact that none of the studies reported high levels of anxious-avoidant attachment, and that all of the studies reported average or above average levels of securely attached infants.

\section{Selective Parenting}

Ahnert and colleagues (Ahnert \& Lamb, 2000, 2001; Ahnert, Lamb, \& Seltenheim, 2000) have conducted a series of studies with German infants and parents which offered a unique opportunity to study cultural differences. These researchers were able to study parent child relationships before, during, and after the reunification of East and West Germany. East Germany was known for its rigid child rearing practices and valued child independence at an early age (Uhlendorff, 2004), which included children's introduction to socially run daycare facilities. West Germany, in contrast, fostered a more nurturing and sensitive role on the part of mothers, with maternity leave being granted from employment for up to three years to care for their children. Yet when the pattern of attachment security between East and West German infants was compared, the rates of secure attachment were virtually identical at $49 \%$ and $50 \%$ respectively (Ahnert \& Lamb, 2001). Another result of interest was the high rate of infants identified within the avoidant category from East Germany during all three time periods (before, during and after reunification), whereas the West German infants assessed before and after reunification showed a higher than average classification in the disorganized category. The results from the studies of post reunified Germany suggest that the culture is associated with a higher than average level of infants classified with avoidant attachment (Ahnert $\&$ Lamb, 2001). Given that anxious-avoidant attachment has typically been regarded as a rare form of attachment (True, Pisani, \& Oumar, 2001) and that German culture would appear to emphasize nurturing parenting with a Western orientation, questions inevi- tably surface about the reliability of the attachment concept across cultures.

\section{Shared Parenting}

The central focus of attachment theory has been on the dyadic relationship between the infant and the mother or primary caregiver. But since many cultures involve other family members or even community members in significant parenting roles, these cultures offer an opportunity to explore the implications of shared parenting for attachment security.

The kibbutzim in Israel were collective farms founded upon socialist principles of an equal sharing of responsibilities and rewards among community members with no individual having greater hierarchal (social or economic) importance. These communities are unique in that they are the only cultural group that has adopted an arrangement where children sleep in a separate location from their parents while being tended at night by non-family members (van IJzendoorn \& Sagi, 1999). The intention of this arrangement was to socialize children for communal life and to create a sense of group cohesion and, thus, people who could socially and emotionally function within the community. This would mean that if a secure attachment was formed it would have been secondary to the core goal of the community.

Sagi, van IJzendoorn, Aviezer, Donnell, \& Mayseless (1994) conducted a study that compared 25 family-based sleeping infants with 23 communalbased sleeping infants from a kibbutz. These authors concluded that home-based infants had a higher rate of secure attachment. The distribution of attachment security among the home-based infants was $0 \%$ anxious-avoidant, $60 \%$ secure, $8 \%$ anxious-resistant, and $32 \%$ disorganized, whereas among the communal infants it was $0 \%$ anxious-avoidant, $26 \%$ secure, and $30 \%$ anxious-resistant, and $44 \%$ disorganized. Furthermore, the average rate of disorganized attachment was $37 \%$, almost reaching the rate of secure attachment of $44 \%$ with the kibbutz. These findings coincide with Sagi et al's earlier study in 1985 concluding that " $41 \%$ of kibbutz infants were insecurely attached to their mothers" (Oppenheim, 1998, p. 80). Thus, the form of shared parenting adopted by the kibbutzim appeared to be associated with an overrepresentation of infants classified as anxious-resistant and an under representation of infants in the anxious-avoidant category (van IJzendoorn \& Sagi, 1999). 
African cultures such as the Dogon, Efe, and Gusii also rely on multiple caregivers to maintain and ensure child subsistence, although the degree and role of the caregiver is diverse among each culture. The African cultures are known for feeding infants on demand, and keeping infants in close proximity. True's (1994) study on the Dogon of Mali showed a high percentage of disorganized infants (23\%), a high rate of secure infant attachment (69\%), an absence of the anxious-avoidant classification, and an under-representation of infants in the anxious-resistant category (8\%)(cited by van IJzendoorn \& Sage, 1999). These results were supported by another study conducted by True et al. (2001) with a sample of 42 infants in which they found the attachment distribution to be $67 \%$ secure, $8 \%$ anxious-resistant, $25 \%$ disorganized and again an absent of the anxious-avoidant category. Similarly, Kermoian \& Leiderman (1986) studied 26 Gusii infants ranging from 8 to 27 months in age, and reported $61 \%$ of the infants being classified as securely attached. Unfortunately these authors did not identify the type of insecure attachment these infant possess. Thus, when the SSP is used to assess attachment security among children in these cultures, the category distribution has similar outcomes, having an over representation in one of the insecure groups despite the fact that the cultures pride themselves on sensitive parenting and instant responses to infant cues.

In summary, attachment theory argues that sensitive caregiving leads to securely attached children. Yet in the above cross-cultural studies, where maternal sensitivity is thought to be high and the caregiving is nurturing, the rate of security is inconsistent with the sensitivity hypothesis.

\section{Aboriginal Parenting}

Many descriptions and assertions of Aboriginal parenting exists in the literature (RCAP, 1996; Report of the Aboriginal Committee, 1992; Report of the First Nation's Child and Family Task Force, 1993), however, there has been relatively little research that has been conducted with Aboriginal Peoples analyzing parenting practices (Gfellner, 1990) and even less research related to attachment theory (Christensen \& Manson, 2001; McShane \& Hastings, 2004). The authors could find no research that has examined the pattern of attachment security using the SSP with parents and children from Aboriginal communities.
Therefore, in this section we will review some of the descriptions of Aboriginal parenting that have appeared in the literature and which may have a bearing on attachment theory.

Aboriginal cultures in Canada are similar to other cultures in that they cannot be viewed as homogeneous (Isajiw, 1999), rather they have characteristics specific to their geographic locations and social networks (Preston, 2002). Although there are differences between Aboriginal Peoples and differences within each People group in terms of culture, there are nevertheless some consistently reported generalizations, based upon observations and shared experience, that suggest Aboriginal parenting is often characterized by shared parenting (Red Horse, Lewis, Feit, \& Decker, 1978) and selective parenting.

Aboriginal families do not adhere to the linear sequence of the mother as the sole contributor to the child's physical and emotional well-being (Weaver \& White, 1997). There is no pressure put on the sole relationship between mother and infant in most $\mathrm{Ab}$ original cultures (Report of the Aboriginal Committee, 1992). The 'nuclear' family of mother, father, and children is considered a household within the family (Red Horse, 1980). Aboriginal concepts of the family range from the extended family concept, where lineage and bloodlines are important, to the wider view where clans, kin, and totems can include elders, leaders, and communities (Okpik, 2005; Red Horse, 1980). Hallowell (1955) observed this centripetal tendency of Saulteaux (Ojibwe) kinship structure where people were continually included as part of the family, regardless of bloodline. These members all share a collective responsibility for the caring and nurturing of the child (McShane \& Hastings, 2004) and keep a watchful eye on young children in the community (Lame Deer \& Erdoes, 1994). The bond between the child and the parent and other caregivers in Aboriginal culture, therefore, is multi-layered rather than dyadic. The effect of these diverse, overlapping bonds is to create a dense network of relationships within which sharing and obligations of mutual aid ensure that an effective safety net is in place (Brendtro \& Brokenleg, 1993). Attachment theory, in contrast, concentrates on the linear relationship between the mother and the infant and does not include in the theory wider social relationships except to suggest that the mother infant relationship becomes a template for all future relationships (Lewis, 2005). Attachment 
theory, therefore, does not fully reflect the reality of an Aboriginal infant's life and socialization experiences. Additionally, the qualities that emerge from the mother-infant relationship do not necessarily transfer to other relationships because the roles others play in the child's life take on a different meaning.

Children hold a special place in Aboriginal cultures. According to many Aboriginal traditions, children are gifts from the Creator (RCAP, 1996). This is a spiritually based view of the world and contains a belief that everything will work out in the end, that momentary struggles are no more than a temporary tribulation or lessons in life that need to be learned. As a result, parents take a long term view of the child, which includes a sense of destiny, and which means that the parent's role is not to shape and create behaviour but to provide a context for its expression. This can also be seen in Aboriginal parents preferring non-verbal teaching and learning styles where they observe their children's behaviours rather than intervene (Letourneau, Hungler, \& Fisher, 2005). Children are allowed to make many decisions because they are considered a person and free to explore their own environment (McPherson \& Rabb, 2001). In comparison to Canadian mainstream parenting practices, Aboriginal values and parenting practices would be interpreted as passive, permissive, and lacking control of children's behaviour (Hamilton \& Sinclair, 1991).

Kelso \& Attneave (1981), for instance, commented on the role of emotional restraint in the parenting practices of Aboriginal parents, which was considered a traditional parenting style associated with the demands of a nomadic life. Even though the traditional context has disappeared, the child rearing practice has persisted. Hallowell's (1955) experiences with living with the Saulteaux on the east side of Lake Winnipeg bear out this common practice. Dr. Claire Brant (1990), a Mohawk psychiatrist, observed in his experiences with the Cree of James Bay, that the practice of inhibiting aggression was a prevalent parenting strategy. The behaviour has been misinterpreted as psychopathology and/or conflict suppression by clinicians unaware of the cultural values that have shaped this behaviour.

One of the cornerstones of attachment theory is the emphasis on the mother's ability to be sensitive to her infant's signals or cues and responsive to the infants needs. In a context of multiple caregivers living in the same household, the mother can afford to be less vigilant and can have an expectation that someone will be available to attend to the infant's signals and needs. The implication in terms of attachment theory is that such practices by a mother would be considered insensitive and when assessed in the SSP it is possible that the child would reflect an anxiousavoidant pattern, when in fact the child's behaviour would be consistent with his or her social context.

\section{Summary and Conclusion}

The ability to capture an infant's quality of relationship to a caregiver using the SSP has been challenging because of the variety of contexts in which families live and the roles adults play within a child's life. The SSP has been modified to compensate overstressed infants and those whose proximity seeking behaviours were not normally activated by the procedure. This raises the question of the extent to which the SSP can be modified before it is unable to measure what was originally intended.

van IJzendoorn (1993) acknowledges that infants in multiple caregiving cultures can establish a network of attachment relationships but the primary relationship is still with their mothers. Questions arise as to what the distribution of attachment types should look like when the measure is applied to many family contexts across numerous cultural groups. The larger issue is whether attachment classification matters if the family in question sees the infant developing along culturally expected goals. If families follow culturally congruent approaches to parenting, these may not be in accord with what attachment theory suggests. For instance, in cultures with shared parenting practices, such as Aboriginal families, it is less clear who should be included in parenting skills training. Therefore, the relevancy of attachment theory may apply only to those parents who are intent on developing certain characteristics within their children.

The larger social and historical context of Aboriginal realities in Canada, such as colonization, residential schools and their lingering affects, racism, poverty, high rates of suicide, high rate of child welfare involvement, school dropout rates, etc. renders concerns about maternal sensitivity as potentially trivial. Many of these social-historical forces have destroyed relationships that many Aboriginal families have tried to develop with their children. In these situations, it is important that attachment theory does not get over-extended in application by addressing mater- 
nal-infant relationships while ignoring social forces acting upon the family. Waters, Corcoran, \& Anafarta (2005) acknowledges the limited domain which attachment theory addresses, that is, the secure base facet of specific relationships, usually the mother. Therefore, a broader context of attachment theory as it relates to different contexts is not only desirable but clearly necessary in order to promote understanding and avoid misperceptions.

Instead of continuing the focus of research on universality, which some researchers consider moot (Bretherton \& Waters, 1985), others consider it unresolved (LeVine \& Miller, 1990), and yet others consider it inaccessible (Grossmann \& Grossmann, 1990), researchers are now considering the issue of conditional strategies in parenting (Main, 1990). Recognizing that the selection of parenting strategies reflects cultural norms, conditional strategies are considered to be those parenting strategies that are most useful given the mores and expectations of a society. Accordingly, Bretherton (1995) has noted that to better explore cultural variations in attachment organization, attachment researchers need to develop ecologically valid, theory driven observational and interview measures that are tailored to specific cultures and based on deeper knowledge of parents' and children's culture-specific folk theories about family relationships and attachment. In Aboriginal cultures this would imply exploring extended family connections, clans and kinship systems and their influence and role in parenting.

\section{References}

Aboriginal Head Start. (2006). Aboriginal Head Start (AHS) in Urban and Northern Communities, Program overview: Public Health Agency of Canada.

Ahnert, L., \& Lamb, M. E. (2000). Infant-care provider attachments in contrasting care settings II: Individual-oriented care after German reunification. Infant Behavior and Development, 23(2), 211-222.

Ahnert, L., \& Lamb, M. E. (2001). The East German child care system: Associations with caretaking and caretaking beliefs, and children's early attachment and adjustment. American Behavioral Scientist, 44(11), 1843-1863.

Ahnert, L., Lamb, M. E., \& Seltenheim, K. (2000). Infantcare provider attachments in contrasting child care settings I: Group oriented care before German reuni- fication. Infant Behavior and Development, 23(2), 197-209.

Ainsworth, M. D. S., Bell, S., \& Stayton, D. (1974). Infant-mother attachment and social development: socialization as a product of reciprocal responsiveness to signals. In M. P. Richards (Ed.), The integration of the child into the social world (pp. 99-135). Cambridge: UK: Cambridge University Press.

Ainsworth, M. D. S., Blehar, M. C., Waters, E., \& Wall, S. (1978). Patterns of attachment: A psychological study of the strange situation. Hillsdale: NJ: Lawrence Erlbaum Associates.

Ainsworth, M. D. S., \& Marvin, R. S. (1994). On the shaping of attachment theory and research: An interview with Mary D. S. Ainsworth (Fall 1994). Monographs of the Society for Research in Child Development, 60 $(2 / 3), 2-21$.

Bournstein, M. H., Tamis-LeMonda, C. S., Tal, J., Ludemann, P., Toda, S., Rahn, C. W., Pecheux, M.-G., Azuma, H., \& Vardi, D. (1992). Maternal responsiveness to infants in three societies: The United States, France, and Japan. Child Development, 63(4), 808-821.

Bowlby, J. (1969). Attachment and loss: Attachment (Vol. 1). London: Pimlico.

Bowlby, J. (1973). Attachment and loss: Separation: Anger and anxiety (Vol. 2). London: Pimlico.

Bowlby, J. (1980). Attachment and loss: Loss (Vol. 3). London: Pimlico.

Brant, C. (1990). Native ethics and rules of behaviour. $\mathrm{Ca}$ nadian Journal of Psychiatry, 35(August), 534-539.

Brendtro, L. K., \& Brokenleg, M. (1993). Beyond the curriculum of control. Journal of Emotional and Behavioural Problems, 1(4), 5-11.

Bretherton, I. (1985). Attachment theory: Retrospect and prospect. In I. Bretherton \& E. Waters (Eds.), Growing points of attachment theory and research (Vol. 50 (1/2), pp. 3-35): Monographs of the Society for Research in Child Development.

Bretherton, I. (1995). A communication perspective on attachment relationships and internal working models. Monographs of the Society for Research in Child Development, 60 (2/3), 310-329.

Bretherton, I., \& Waters, E. (Eds.). (1985). Growing points of attachment theory and research (Vol. 50 (1-2, Serial No. 209)): Monographs of the Society for Research in Child Development. 
Carlson, E. A. (1998). A prospective longitudinal study of attachment disorganization/disorientation. Child Development, 69(4), 1107-1128.

Cassidy, J., \& Shaver, P. R. (Eds.). (1999). Handbook of attachment: Theory, research, and clinical applications. New York: The Guilford Press.

Christensen, M., \& Manson, S. (2001). Adult attachment as a framework for understanding mental health and American Indian families. American Behavioral Scientist, 44(9), 1447-1465.

Crittenden, P. M., \& Claussen, A. H. (Eds.). (2000). The organization of attachment relationships: Maturation, culture, and context. Cambridge, UK: Cambridge University Press.

Gfellner, B. M. (1990). Culture and consistency in ideal and actual child-rearing practices: A study of Canadian Indian and white parents. Journal of Comparative Family Studies, XXI(3), 413-423.

Gibson, F. L., Ungerer, J. A., McMahon, C. A., Leslie, G. I., \& Saunders, D. M. (2000). The mother-child relationship following in vitro fertilisation (IVF): Infant attachment, responsivity, and maternal sensitivity. Journal of Child Psychology \& Psychiatry, 41(8), 1015-1023.

Grossmann, K. E., \& Grossmann, K. (1990). The wider concept of attachment in cross-cultural research. Human Development, 33, 31-47.

Hallowell, A. I. (1955). Culture and experience. Philadelphia: University of Pennsylvania Press.

Hamilton, A. C., \& Sinclair, C. M. (1991). Report of the Aboriginal justice inquiry of Manitoba: The justice system and Aboriginal people.

Harwood, R. L., Miller, J. G., \& Irizarry, N. L. (1995). Culture and attachment: Perceptions of the child in context. New York, NY: The Guilford Press.

Isajiw, W. W. (1999). Understanding diversity: Ethnicity and race in the Canadian context. Toronto: Thompson Press.

Karen, R. (1990). Becoming attached. The Atlantic Monthly, 35-70.

Karen, R. (1994). Becoming attached: Unfolding the mystery of the infant-mother bond and its impact on later life. New York: Warner Books.

Kelso, D., \& Attneave, C. (1981). Bibliography of North American Indian mental health. Westport: CT: Greenwood Press.
Kermoian, R., \& Leiderman, P. H. (1986). Infant attachment to mother and child caretaker in an East African community. International Journal of Behavioral Development, 9(4), 455-469.

Lame Deer, J. F., \& Erdoes, R. (1994). Lame Deer: Seeker of visions. New York: Washington Square Press.

Letourneau, N. L., Hungler, K. M., \& Fisher, K. (2005). Low-income Canadian Aboriginal and non-Aboriginal parent-child interactions. Child: Care, Health and Development, 31(5), 545-554.

LeVine, R. A., \& Miller, P. M. (1990). Commentary. Human Development, 33, 73-80.

Lewis, M. (2005). The child and its family: The social network model. Human Development, 48(1-2), 8-27.

Main, M. (1990). Cross-cultural studies of attachment organization: Recent studies, changing methodologies, and the concept of conditional strategies. Human Development, 33, 48-61.

Main, M., \& Hesse, E. (1992). Disorganized/disoriented infant behaviour in the strange situation: Lapses in the monitoring of reasoning and discourse during the parent's adult attachment interview and dissociative states. In J. Stevenson-Hinde, C. M. Parkes \& S. D. (Eds.), Attachment and psychoanalysis. Rome: Gius, Laterza and Figli.

Main, M., \& Solomon, J. (1986). Discovery of a new, insecure disorganized/disoriented attachment pattern. In T. B. Brazelton \& M. Yogman (Eds.), Affective Development in Infancy. Norwood: NJ: Ablex.

Main, M., \& Solomon, J. (1990). Procedures for identifying infants as disorganized/disoriented during the Ainsworth strange situation. In D. Greenberg, D. Cicchetti \& E. M. Cummings (Eds.), Attachment in the preschool years (pp. 121-160). Chicago: University of Chicago Press.

McCain, M. N., \& Mustard, J. F. (1999). The early years study: Reversing the real brain drain. Toronto, ON: Children's Secretariat.

McPherson, D., H., \& Rabb, J. D. (2001). Indigeneity in Canada: Spirituality, the sacred and survival. International Journal of Canadian Studies, 23(Spring), 57-79.

McShane, K. E., \& Hastings, P. D. (2004). Culturally sensitive approaches to research on child development and family practices in first peoples communities. First Peoples Child and Family Review, 1(1), 38-44. 


\section{Is Attachment Theory Consistent with Aboriginal Parenting Realities?}

Morton, N., \& Browne, K. D. (1998). Theory and observation of attachment and its relation to child maltreatment: A review. Child Abuse and Neglect, 22(11), 1093-1104.

Okpik, A. (2005). We call it survival: Nunavut Arctic College.

Oppenheim, D. (1998). Perspectives on infant mental health from Isreal: The case of changes in collective sleeping on the kibbutz. Infant Mental Health Journal, 19(1), 76-86.

Preston, R. (2002). Cree Narrative (2nd ed.). McGill: Queen's University Press.

RCAP. (1996). The Royal Commission on Aboriginal Peoples. Ottawa: Canada.

Red Horse, J. G. (1980). Family structure and value orientation in American Indians. Social Casework, 61(8), 462-467.

Red Horse, J. G., Lewis, R., Feit, M., \& Decker, J. (1978). Family behaviour of urban American Indians. Social Casework, 59(2), 67-72.

Report of the Aboriginal Committee. (1992). Liberating our children: Liberating our nations. Vancouver, BC: Community Panel Family and Children's Services Legislation Review in British Columbia.

Report of the First Nation's Child and Family Task Force. (1993). Children first: Our responsibility: Assembly of Manitoba Chiefs, Department of Indian and Northern Affairs, Manitoba Minister of Family.

Rothbaum, F., Weisz, J., Pott, M., Miyake, K., \& Morelli, G. (2000). Attachment and culture: Security in the United States and Japan. American Psychologist, 55(10), 1093-1104.

Rycus, J. S., \& Hughes, R. C. (1998). Field guide to chld welfare, Volume 3: Child development and child welfare. Washington, DC: Child Welfare League of America.

Sagi, A. (1990). Attachment theory and research from a cross-cultural perspective. Human Development, 33, $10-22$.

Sagi, A., van Ijendoorn, M. V., Aviezer, O., Donnell, F., \& Mayseless, O. (1994). Sleeping out of home in a kibbutz communal arrangement: It makes a difference for infant-mother attachment. Child Development, 65(4), 992-1004.

Sroufe, A. L., Egeland, B., Carlson, E. A., \& Collins, W. A. (2005). The development of the person: The Minnesota study of risk and adaptation from birth to adulthood. New York, NY: Guilford Press.

Sroufe, L. A., Fox, N., \& Pancake, V. (1983). Attachment and dependency in developmental perspective. Child Development, 54(6), 1615-1627.

Takahashi, K. (1986). Examining the strange situation procedure with Japanese mothers and 12-month-old infants. Developmental Psychology, 22, 265-270.

True, M. M., Pisani, L., \& Oumar, F. (2001). Infant-mother attachment among the Dogon of Mali. Child Development, 72(5), 1451-1466.

Uhlendorff, H. (2004). After the wall: Parental attitudes to child rearing in East and West Germany. International Journal of Behavioral Development, 28(1), 71-82.

van IJzendoorn, M. H. (1990). Developments in CrossCultural Research on Attachment: Some Methodological Notes. Human Development, 33, 3-9.

van IJzendoorn, M. H. (1993). Commentary. Human Development, 33, 3-9.

van IJzendoorn, M. H., \& Sagi, A. (1999). Cross-cultural patterns of attachment: Universal and contextual dimensions. In J. Cassidy \& S. P. R. (Eds.), Handbook of attachment: Theory, research and clinical applications (pp. 713-734). New York: The Guilford Press.

Vereijken, C. M. J. L., Riksen-Walraven, J. M., \& KondoIkemura, K. (1997). Maternal sensitivity and infant attachment security in Japan: A longitudinal study. International Journal of Behavioral Development, 21(1), 35-49.

Waters, E., Corcoran, D., \& Anafarta, M. (2005). Attachment, other relationships, and the theory that all good things go together. Human Development, 48, 80-84.

Weaver, H., \& White, B. J. (1997). The Native American family circle: Roots of resiliency. Journal of Family Social Work, 2(1), 67-80. 